\title{
The new species Neoceroplatus betaryiensis nov. sp. (Diptera: Keroplatidae) from Neotropical Region
}

\author{
Rafaela Lopes Falaschi'; Grant A. Johnson² \& Cassius Vinicius Stevani ${ }^{3}$ \\ 1 Universidade Estadual de Ponta Grossa (UEPG), Departamento de Biologia Estrutural, Molecular e Genética, Programa de Pós-Graduação \\ em Biologia Evolutiva. Ponta Grossa, PR, Brasil. ORCID: http://orcid.org/0000-0002-3046-5744. E-mail: rlfalaschi@gmail.com \\ 2 Instituto de Pesquisas da Biodiversidade (IPBI0). Iporanga, SP, Brasil. ORCID: http://orcid.org/0000-0002-6503-3976. \\ E-mail: grant.johnson4231@gmail.com \\ 3 Universidade de São Paulo (USP), Instituto de Química (IQ), Departamento de Química Fundamental. São Paulo, SP. Brasil. \\ ORCID: http://orcid.org/0000-0002-7209-7476. E-mail: stevani@iq.usp.br
}

Abstract. The species Neoceroplatus betaryiensis sp. nov. is presented here with the diagnosis of the species with indication of the ZooBank number, making this publication the valid description of the species.

Key-Words. Unavailable name; Nomenclatural act; Taxonomy; Keroplatinae.

\section{INTRODUCTION}

The Fourth Edition of the International Code of Zoological Nomenclature (ICZN, 1999) gives specific rules for the availability of species names. One of them, in the amendment for names published in electronic publications, is that the work be registered in ZooBank before it is published and that such registration be indicated in the publication itself (ICZN, 2012). A new species of the genus Neoceroplatus was recently published (Falaschi et al., 2019) but the paper did not indicate the ZooBank registration, rendering it as an unavailable name. A diagnosis of the species with indication of the ZooBank number is given here, making this publication the valid description of the species. The detailed description in Falaschi et al. (2019) complements the diagnosis included here.

\section{Taxonomical Results}

\section{Neoceroplatus Edwards, 1941: 304 (as Ceroplatus subgenus)}

Type species: Ceroplatus minimax Edwards, 1934, by original designation.

\section{Neoceroplatus betaryiensis Falaschi, Johnson \& Stevani nov. sp.}

Neoceroplatus betaryiensis Falaschi, Johnson \& Stevani nov. sp. (in Falaschi et al., 2019), unavailable name.
Material examined: Holotype: Male, BRAZIL, São Paulo, Iporanga, Reserva Betary, IPBio - Instituto

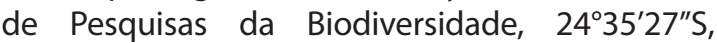
$48^{\circ} 37^{\prime} 44^{\prime \prime} \mathrm{W}, 120 \mathrm{~m}$, manual collection on the underside of a leaf (on June 14 $4^{\text {th }} 2017$ one larva was collected and on August 24 2017 the adult male emerged), Domingos, A.H.R., Santos, I. \& Johnson, G.A. cols. [MZUSP-MZ052800] (specimen pinned with terminalia on permanent slide). Paratypes: Two females, same data as holotype, except 01.v.2017 (larva collected) 24.v.2017 (adult female emerged) [MZUSP-MZ052801] (specimen pinned), [MZUSP-MZ052802 (specimen on permanent slide); one larva, same data as holotype, except 15.v.2017, [MZUSP-MZ052803] (in 80\% ethanol); two larvae, same data as holotype, except 16.iv.2017, [MZUSP-MZ052804] (in 80\% ethanol), [MZUSP-MZ052805] (in permanent slide); pupa exuvium, same data as holotype, except 24.viii.2017, [MZUSP-MZ052806] (in permanent slide); net remains, same data as holotype, except 24.viii.2017, [MZUSP-MZ052807] (in 80\% ethanol). Holotype and Paratypes deposited in the Museu de Zoologia, Universidade de São Paulo (MZUSP), Brazil.

Etymology: The specific epithet refers to the Betary brook, in whose banks the specimens were collected.

\section{Diagnosis and Comments}

Neoceroplatus betaryiensis nov. sp. can be distinguished from the other Neotropical Neoceroplatus, 
especially from $N$. dissimilis, its closest species, by the shape of the genitalia, particularly the gonostylus (see Falaschi et al., 2019, Figs. S3E, S4B, C) and the absence of spines in the gonostylus as appears in N. paicoenai.

Comments: The full description and images are available in Falaschi et al. (2019).

\section{ACKNOWLEDGEMENTS}

We thank Neal Evenhuis for calling our attention to the problem in the original publication. This paper is a product of a project supported by Fundação de Amparo à Pesquisa do Estado de São Paulo (grants FAPESP 2013/16885-1 and 2017/22501-2) to CVS, and by the Coordenação de Aperfeiçoamento de Pessoal de Nível Superior - Brasil (CAPES - Finance Code 001) to RLF. This work was also partially supported by funding from the Office of Naval Research Global through grant ONR N62909-17-1-2103 to CVS.

\section{REFERENCES}

Edwards, F.W. 1941. Mycetophilidae (Diptera) collected by the expedition to Matto Grosso of the Brazilian Zoological Club, in July 1939. Revista de Entomologia, 12(1-2): 303-314.

Falaschi, R.L.; Amaral, D.T.; Santos, I.; Domingos, A.H.R.; Johnson, G.A.; Martins, A.G.S.; Viroomal, I.B.; Pompéia, S.L.; Mirza, J.D.; Oliveira, A.G.; Bechara, E.J.H.; Viviani, V.R. \& Stevani, C.V. 2019. Neoceroplatus betaryiensis nov. sp. (Diptera: Keroplatidae) is the first record of a bioluminescent fungus-gnat in South America. Nature, Scientific Reports, 9: 11291, 1-9. DOI

International Commission on Zoological Nomenclature (ICZN). 1999. International Code of Zoological Nomenclature. Fourth edition. International Trust for Zoological Nomenclature, London, ICZN. $x x i x+306 p$.

International Commission on Zoological Nomenclature (ICZN). 2012. Amendment of Articles 8, 9, 10, 21 and 78 of the International Code of Zoological Nomenclature to expand and refine methods of publication. Bulletin of Zoological Nomenclature, 69(3): 161-169. 